\title{
A STUDY OF COMPARISON BETWEEN TRAMADOL AND ONDANSETRON TO ALLEVIATE PAIN DURING PROPOFOL ADMINISTRATION
}

\author{
Shaiqa Manzoor ${ }^{1}$, Mohammad Sadiq Malla², Arshid Ahmad Sofi ${ }^{3}$, Sameena Ashraf ${ }^{4}$ \\ ${ }^{1}$ Senior Resident, Department of Anaesthesiology, SKIMS, Bemina, Srinagar. \\ ${ }^{2}$ Assistant Professor, Department of Anaesthesiology and Critical Care, Govt. Medical College, Srinagar. \\ 3 Senior Resident, Department of Anaesthesiology and Critical Care, Govt. Medical College, Srinagar. \\ ${ }^{4}$ Consultant, Department of Obstetrics and Gynaecology, District Hospital, Baramulla, Kashmir.
}

\section{BACKGROUND}

ABSTRACT

Propofol is a commonly used anaesthetic agent for induction and maintenance of anaesthesia. Its intravenous administration is associated with pain, which is reduced by different pharmacological methods. Our study evaluated comparative effectiveness of ondansetron and tramadol in reducing this pain.

\section{MATERIALS AND METHODS}

After approval by the Institutional Ethical Committee and an informed written consent, 120 American Society of Anaesthesiologist (ASA) Grade I and II patients of either sex, aged 18 - 60 years, undergoing various surgeries using general anaesthesia were selected. Patients with known hypersensitivity to propofol, ondansetron and tramadol, cardiac conduction defects and epilepsy were excluded. In our study, patients were randomly assigned to three groups of 40 patients each (Group 1, n= 40): Patients received upto $2 \mathrm{~mL}$ pre-treatment $50 \mathrm{mg}$ tramadol in the saline, (Group 2, $\mathrm{n}=40$ ): $4 \mathrm{mg}$ ondansetron in the saline (2 $\mathrm{mL}$ ), (Group 3, $n=40$ ): normal saline $2 \mathrm{~mL}$. Drugs were given intravenously for a period of 10 seconds, while the venous drainage was occluded by placing an air-filled tourniquet (pressure inflated to $70 \mathrm{mmHg}$ ) on the upper arm by an assistant for one minute. Then patient was given intravenous propofol (1\%) $2 \mathrm{mg} / \mathrm{kg}$ over a period of 10 seconds. The patient was asked a standard question "Is the injection comfortable?" The verbal response and behavioural signs such as facial grimacing, arms withdrawal or tears were recorded. A score of 0 to 3 corresponding to $0=$ No pain, $1=$ Mild pain, $2=$ Moderate pain and $3=$ Severe pain will be noted.

\section{RESULTS}

The overall incidence of pain was $85 \%$ in the saline group, which was decreased to $12.5 \%$ and $20 \%$ after tramadol and ondansetron pre-treatment respectively. Pain severity was significantly less in patients receiving drugs for pre-treatment than those receiving saline $(\mathrm{p}<0.0001)$. No significant association was found between gender and incidence and severity of pain $(\mathrm{p}=$ 0.70 ). The incidence and severity of pain in patients above 50 years old was significantly less than patients below 50 years old (0.0001).

\section{CONCLUSION}

Tramadol and ondansetron pre-treatment provides a simple and safe method of reducing propofol injection pain. Both are equally effective, but ondansetron has an advantage in preventing postoperative nausea and vomiting.

\section{KEYWORDS}

Propofol, Ondansetron, Tourniquet.

HOW TO CITE THIS ARTICLE: Manzoor S, Malla MS, Sofi AA, et al. A study of comparison between tramadol and ondansetron to alleviate pain during propofol administration. J. Evolution Med. Dent. Sci. 2018;7(02):242-245, DOI: 10.14260/jemds/2018/54

\section{BACKGROUND}

Propofol is a popular anaesthetic intravenous agent, especially for brief cases, day surgery or when laryngeal mask airway is to be used. Propofol can also be used in total intravenous anaesthesia (TIVA) technique for the maintenance of anaesthesia and sedation. It has also been used for the prevention of emesis.(1) Tracheal intubation without neuromuscular blocking agents(2) and the treatment of pruritus.(3,4) Propofol has a highest incidence of pain on injection when compared to other intravenous anaesthetic

'Financial or Other Competing Interest': None.

Submission 16-09-2017, Peer Review 21-12-2017,

Acceptance 27-12-2017, Published 08-01-2018.

Corresponding Author:

Dr. Mohammad Sadiq Malla,

Faculty Quarter E,

Doctors Hostel, Bemina, Srinagar.

E-mail: drsadiqanaes@gmail.com

DOI: $10.14260 /$ jemds/2018/54 agents. The incidence of pain on induction with thiopentone is about $7 \%$,(5) while as that of propofol pain varies between $28 \%-90 \%$ in adults during induction of anaesthesia. Propofol has been commonly used for induction and maintenance of anaesthesia, but pain of propofol injection can be extremely distressing to the patients. Pain on injection of propofol can be immediate or delayed. Immediate pain probably results from direct irritant effect and delayed pain probably results from an indirect effect via kinin cascade. Delayed pain has a latency of between 10 - 20 secs.(6) Up to now, the mechanism of pain due to propofol injection has been unclear. Propofol belong to the group of phenols and can directly irritate the skin, mucous membrane and venous intima and could immediately stimulate nociceptors and free nerve endings. (7) By its indirect action on the endothelium, it was considered that propofol activate the kallikrein-kinin system and releases bradykinin through producing venous dilation and hyperpermeability, which increases the contact between aqueous phase of propofol. 
Wong and Cheong reported that pre-treatment with tramadol was as effective as lidocaine in alleviating pain on propofol injection.(8) Ye et al demonstrated that ondansetron, a specific 5 -HT antagonist, blocks Na channels in rat brain neurons. They also found that ondansetron is 15 times more potent than lidocaine in causing numbness when injected under the skin.(7) Our study evaluated the incidence of pain during propofol injection and compared the effectiveness of ondansetron and tramadol to reduce pain during propofol injection.

\section{MATERIALS AND METHODS}

This randomised prospective double-blind clinical study was conducted in the Postgraduate Department of Anaesthesiology and Critical Care, Government Medical College, Srinagar. The study was conducted after approval by the Institutional Ethical Committee and an informed written consent was obtained from all the patients for participation in this study. Patients selected for surgery were among those already admitted in different units of the hospital. 120 American Society of Anesthesiologist (ASA) Grade I and II patients of either sex, aged 18 - 60 years undergoing various surgeries using general anaesthesia were randomly selected. Pre-anaesthetic evaluation was done at least $24 \mathrm{hrs}$. prior to surgery. Patients with known hypersensitivity to propofol, ondansetron or tramadol or concomitant analgesic or sedative medication; presence of infection on the dorsum of the left hand; indications for rapid sequence intubation; presence of cardiac conduction defects; epilepsy and use of antiarrhythmic medications; thin dorsal veins and uncooperative patients were excluded. In our study, patients were randomly allocated to three groups of 40 patients each. Randomisation was done by using computer generated table with random numbers. No premedication was administered. A 20-gauge cannula was placed into the largest vein on the dorsum of the left hand after placing the routine monitors include lead II electrocardiogram, non-invasive blood pressure and pulse oximeter-

- (Group 1, $\mathrm{n}=40$ ): Patients received upto $2 \mathrm{~mL}$ pretreatment $50 \mathrm{mg}$ tramadol in the saline.

- (Group 2, $\mathrm{n}=40): 4 \mathrm{mg}$ ondansetron in the saline (2 mL).

- (Group 3, n= 40): normal saline $2 \mathrm{~mL}$.

Drugs were given intravenously for a period of 10 seconds, while the venous drainage was occluded by placing an air-filled tourniquet (pressure inflated to $70 \mathrm{mmHg}$ ) on the upper arm by an assistant. An anaesthetist prepared the solutions and the investigator did not know the contents of the solutions. The occlusion was released after one minute. Then $2 \mathrm{mg} / \mathrm{kg}$ propofol $1 \%$ was injected for a period of over 10 seconds. The drugs in the study were preservative free and at room temperature. No analgesic or sedative was administered before propofol. Another clinician, unaware of the group to which the patients has been allocated assessed the level of pain on injection of propofol. The patient was asked a standard question, "Is the injection comfortable?" The verbal response and behavioural signs such as facial grimacing, arms withdrawal or tears were recorded.

A score of 0 to 3 , corresponding to $0=$ No pain, $1=$ Mild pain, $2=$ Moderate pain, $3=$ Severe pain will be noted.

McCrirrick and Hunter scale of evaluation of propofol injection pain.(9)

\begin{tabular}{|c|c|c|}
\hline Score & $\begin{array}{c}\text { Degree of } \\
\text { Pain }\end{array}$ & Response \\
\hline 0 & None & No response to questioning \\
\hline 1 & Mild & $\begin{array}{c}\text { Pain reported in response to questioning } \\
\text { only without any behavioural signs }\end{array}$ \\
\hline 2 & Moderate & $\begin{array}{c}\text { Pain reported in response to questioning } \\
\text { and accompanied by behavioural or pain } \\
\text { reported spontaneously without } \\
\text { questioning }\end{array}$ \\
\hline 3 & Severe & $\begin{array}{c}\text { Strong vocal response or response } \\
\text { accompanied by facial grimacing, arm or } \\
\text { withdrawal or tears }\end{array}$ \\
\hline
\end{tabular}

The adverse effects, if any, were noted. We injected sedative and opioid after propofol to get the most reliable response of patients. Anaesthetic induction was continued with fentanyl $2 \mu \mathrm{g} / \mathrm{kg}$ and midazolam $0.03 \mathrm{mg} / \mathrm{kg}$ intravenously. Tracheal intubation was facilitated with 0.5 $\mathrm{mg} / \mathrm{kg}$ atracurium and anaesthesia was maintained with isoflurane $1.2 \%$. The patients were extubated after administering muscle relaxation antagonist. Patients were followed up during the first 6 hours and were assessed for pain, swelling or allergic reaction at the injection site of propofol by anaesthesiologist.

\section{Statistical Analysis}

The recorded data was compiled and entered in a spreadsheet (Microsoft Excel) and then exported to data editor of SPSS version 20.09 (SPSS Inc., Chicago, Illinois, USA). Continuous variables were summarised in the form of means and standard deviations and categorical variables were expressed as frequencies and percentages. Graphically, the data was presented by bars and pie diagrams. Analysis of Variance (ANOVA) with least significant difference (LSD) test was employed for comparing continuous variables. Chisquare test or Fisher's exact test, whichever appropriate, was applied for comparing categorical variables. A ' $\mathrm{P}$ ' value of less than 0.05 was considered statistically significant. Using GPower software (version 3.0.10) it was estimated that the least no. of patients required in each group with $80 \%$ power and $5 \%$ significance level is 40 . Since we had to compare three groups in our study, therefore a total of 120 patients were included in our study.

\section{RESULTS}

The study included 120 patients. Mean age of the patients in tramadol group (Group 1), ondansetron group (Group 2) and normal saline group (Group 3) was $41 \pm 10.59$ years, $42.62 \pm$ 10.71 years and $39.57 \pm 8.95$ years respectively and the difference was not significant $(\mathrm{p}=0.223)$. The difference in gender distribution was not significant $(\mathrm{p}=0.521) .65 \%$ were females and $35 \%$ were males in tramadol group (Group 1), $57.5 \%$ were females and $42.5 \%$ were males in ondansetron group (Group 2) and 52.5\% were females and $47.5 \%$ were males in saline group (Group 3). The overall incidence of pain was $85 \%$ in saline group (Group 3), which was reduced to $12.5 \%$ in tramadol group (Group 1) and $20 \%$ in ondansetron group (Group 2). Pain intensity decreased significantly in tramadol group (Group 1) and ondansetron group (Group 2) as compared to saline group (Group 3) [p=0.0001] \{Figure 1\}. Ondansetron and tramadol significantly reduced the severity of propofol injection pain compared to saline group $(p=0.0001)$. Efficacy of ondansetron in alleviating the 
incidence and severity of propofol injection pain was no different from tramadol $(\mathrm{p}=0.546)$ [Figure 2]. 37.1\% females had pain and $42 \%$ males had pain and the difference was not significant $(\mathrm{p}=0.70) .49 .5 \%$ patients above 50 years experienced pain, while only $39.2 \%$ patients below 50 years had pain $(p=0.0001)$. Severity of pain above 50 years was significantly less than patients below 50 years.

\begin{tabular}{|c|c|c|c|}
\hline & \multicolumn{2}{|c|}{ Pain (\%) } \\
\hline & & Yes & No \\
\hline \multirow{3}{*}{ Group } & Tramadol (Group 1) & 12.5 & 87.5 \\
\hline & Ondansetron (Group 2) & 20 & 80 \\
\hline & Normal Saline (Group 3) & 85 & 15 \\
\hline \multicolumn{4}{|c|}{ Table 1. Comparison of Pain among the Groups } \\
\hline
\end{tabular}

\begin{tabular}{|c|c|c|c|c|c|}
\hline & \multicolumn{4}{|c|}{ Severity (\%) } \\
\hline & & 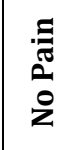 & 忢 & 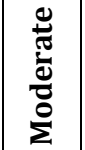 & 峁 \\
\hline \multirow{3}{*}{ Group } & Group 1 (Tramadol group) & 87.5 & 7.5 & 5 & 0 \\
\hline & Group 2 (Ondansetron group) & 80 & 5 & 10 & 5 \\
\hline & Group 3 (Saline group) & 15 & 7.5 & 47.5 & 30 \\
\hline
\end{tabular}

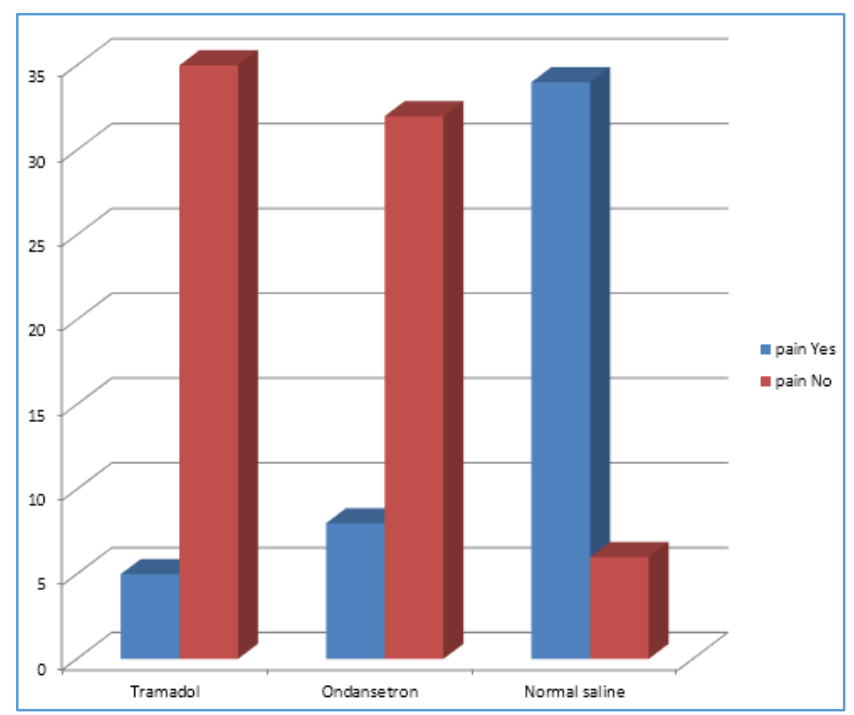

Graph 1. Pain Comparison

\section{DISCUSSION}

Propofol is commonly used for induction and maintenance of anaesthesia, but pain of propofol injection can be extremely distressing to the patients. ${ }^{1}$ Propofol belongs to the group of phenols and can directly irritate the skin, mucous membrane and venous intima and could immediately stimulate nociceptors and free nerve endings. ${ }^{4}$ By its indirect action on the endothelium, it was considered that propofol activates the kallikrein-kinin system and releases bradykinin producing venous dilatation and hyperpermeability, which increases the contact between aqueous phase of propofol and free nerve endings and results in delayed pain within half a minute. 5

Various studies using different agents have been done to decrease the propofol induced pain such as pre-treatment with lignocaine, ephedrine, ondansetron, metoclopramide, nafamostat mesilate, opioids, thiopentone, ketamine.4,9,10,11,1214 McCulloch and Lees showed that the administration of lignocaine $10 \mathrm{mg}$ immediately before propofol injection reduces the incidence of pain from $37.5 \%$ to $17.5 \%$ when using the veins in the back of hand. They did not use premedication and administered propofol over 20 seconds. ${ }^{15}$ Lyons et al reported that the pre-treatment with $10 \mathrm{mg}$ lignocaine seconds before propofol injection could significantly reduce the incidence of injection pain from $64 \%$ to $44 \% .^{16}$ Eriksson et al showed that lignocaine mixed with propofol decreased its $\mathrm{pH}$ resulting in a lower concentration of propofol in the aqueous phase and therefore less pain. ${ }^{17}$ Amina Bashir compared the effectiveness of intravenous lignocaine and tramadol in reducing the pain on propofol injection and showed a significant reduction in pain. ${ }^{18}$ Sushil $\mathrm{P}$ Ambesh showed that the ondansetron pre-treatment alleviates pain on propofol injection. Ye et al demonstrated that ondansetron, a specific 5-HT antagonist blocks sodium channels in rat brain neurons. They found that ondansetron is 15 times more potent as a local anaesthetic than lidocaine. It blocks peripheral 5-HT3 receptors, which are involved in nociceptive pathways. ${ }^{7}$ Ondansetron binds to the opioid $\mu$ receptors in humans and exhibits agonist actions. As a result of its multifaceted action as a sodium channel blocker, a 5-HT 3 receptor antagonist and $\mu$-opioid agonist ondansetron may potentially be used to alleviate pain due to propofol. Till date there is a little published data on efficacy of ondansetron to decrease pain on injection of propofol. Wong and Cheong reported that pre-treatment with tramadol was as effective as lidocaine in alleviating pain on propofol injection. ${ }^{8}$ Tramadol is a centrally acting weak $\mu$-opioid receptor agonist and inhibits noradrenaline reuptake likewise promotes serotonin release. Pang et al showed that tramadol has local anaesthetics effects. ${ }^{6}$ Hamid Zahedi et al evaluated that tramadol and ondansetron significantly reduced the incidence and severity of propofol injection pain. ${ }^{19}$ In this study, we observed a high incidence of pain in $85 \%$ of patients in saline group during propofol injection which was decreased to $12.5 \%$ and $20 \%$ after tramadol and ondansetron pre-treatment respectively. Pain severity was significantly less in tramadol and ondansetron group as compared to saline group $(p=0.0001)$. This study showed that the effect of ondansetron is as good as tramadol in decreasing the incidence and severity of propofol induced pain $(\mathrm{p}=0.546)$ No significant association was found between gender and incidence and severity of pain $(\mathrm{p}=0.70)$. The incidence and severity of pain in patients above 50 years was significantly less than patients below 50 years of age $(p=0.0001)$.

\section{CONCLUSION}

Thus, we conclude that tramadol and ondansetron pretreatment provides a simple and safe method of reducing propofol injection pain, but ondansetron has an advantage in preventing postoperative nausea and vomiting. No adverse effect was noted in any patient.

\section{REFERENCES}

[1] Klement W, Arndt J0. Pain on injection of propofol: effects of concentration and diluent. $\mathrm{Br} \mathrm{J}$ Anaesth 1991;67(3):281-4.

[2] Tan CH, Onsiong MK. Pain on injection of propofol. Anaesthesia 1998;53(5):468-76. 
[3] Briggs LP, Clarke RS, Dundee JW, et al. Use of diisopropyl phenol as a main agent for short procedures. British Journal of Anesthesia 1981;53(11):1197-202.

[4] Ambesh SP, Dubey PK, Sinha PK. Ondansetron pretreatment to alleviate pain on propofol injection: a randomised, controlled double-blinded study. Anesth Analg 1999;89(1):197-9.

[5] Scott RP, Saunders DA, Norman J. Propofol: clinical strategies for preventing the pain of injection. Anaesthesia 1988;43(6):492-4.

[6] Pang WW, Mok MS, Huang S, et al. The analgesic effect of fentanyl, morphine, meperidine and lidocaine in the peripheral veins: a comparative study. Anesth Analg 1998;86(2):382-6.

[7] Ye JH, Mui WC, Ren J, et al. Ondansetron exhibits the properties of a local anesthetic. Anesth Analg 1997;85(5):1116-21.

[8] Wong WH, Cheong KF. Role of tramadol in reducing pain on propofol injection. Singapore Med J 2001;42(5):193-5.

[9] McCrirrick A, Hunter S. Pain on injection of propofol: the effect of injectate temperature. Anaesthesia 1990;45(6):443-4.

[10] Picard P, Tramer MR. Prevention of pain on injection with propofol: a quantitative systematic review. Anesth Analg 2000;90(4):963-9.

[11] Nathanson MH, Gajraj NM, Russell JA. Prevention of pain on injection of propofol: a comparison of lidocaine with alfentanil. Anesth Analg 1996;82(3):469-71.
[12] Nakane M, Iwama H. A potential mechanism of propofol-induced pain on injection based on studies using nafamostat mesilate. $\mathrm{Br} J$ Anaesth 1999;83(3):397-404.

[13] Cheong MA, Kim KS, Choi WJ. Ephedrine reduces the pain from propofol injection. Anesth Analg 2002;95(5):1293-6.

[14] Agarwal A, Ansari MF, Gupta D, et al. Pre-treatmrnt with thiopental for prevention of pain associated with propofol injection. Anesth Analg 2004;98(3):683-6.

[15] McCulloch MJ, Lees NW. Assessment and modification of pain on induction with propofol (Diprivan). Anaesthesia 1985;40(11):1117-20.

[16] Lyons B, Lohan D, Flynn C, et al. Modification of pain injection of propofol. A comparison of pethidine and lignocaine. Anaesthesia 1996;51(4):394-5.

[17] Eriksson M, Englesson S, Niklasson F, et al. Effect of lignocaine and $\mathrm{pH}$ on propofol induced pain. British Journal of Anaesthesia 1997;78(5):502-6.

[18] Bashir A, Abbas Z, Farhat S, et al. A prospective randomised open labelled placebo controlled study comparing intravenous lignocaine and tramadol in reducing the incidence and severity of pain on propofol injection. JK Science 2011;13(3).

[19] Zahedi H, Maheli A, Rostami G. Ondansetron pretreatment reduces pain on injection of propofol. Acta Medica Iranica 2012;50(4):239-43. 